\title{
Relationship of Anti-Mullerian Hormone to Reproductive Traits in Katahdin Ewes Bred in Late Spring or Fall
}

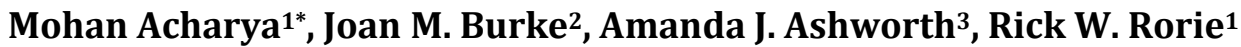 \\ ${ }^{1}$ Department of Animal Science, University of Arkansas, Fayetteville, AR, USA \\ ${ }^{2}$ Dale Bumpers Small Farm Research Center, Agricultural Research Service, US Department of Agriculture, Booneville, AR, USA \\ ${ }^{3}$ Poultry Production and Product Safety Research, Agricultural Research Service, US Department of Agriculture, Fayetteville, \\ AR, USA \\ Email: ^macharya@uark.edu
}

How to cite this paper: Acharya, M. Burke, J.M., Ashworth, A.J. and Rorie, R.W. (2020) Relationship of Anti-Mullerian Hormone to Reproductive Traits in Katahdin Ewes Bred in Late Spring or Fall. $A d$ vances in Reproductive Sciences, 8, 48-56. https://doi.org/10.4236/arsci.2020.81005

Received: December 12, 2019

Accepted: January 13, 2020

Published: January 16, 2020

Copyright $\odot 2020$ by author(s) and Scientific Research Publishing Inc. This work is licensed under the Creative Commons Attribution International License (CC BY 4.0).

http://creativecommons.org/licenses/by/4.0/

\begin{abstract}
Anti-Mullerian hormone (AMH) is an endocrine marker for fertility in many species. This study investigated possible correlations between serum AMH concentrations, mean number of lambs born (out-of-season in spring or fall), and estimated breeding values (EBVs) for number of lambs born (NLB), number of lambs weaned (NLW), maternal weaning weight (MWWT), weaning weight (WWT), and maternal index (determined by Sheep Genetics Australia). Blood was collected at breeding from Katahdin ewes between 0.7 and 7 years of age in $2015(\mathrm{n}=163)$ for the analysis of serum concentrations of AMH. Anti-Mullerian hormone concentration was either expressed quantitatively or divided into quartiles (AMH Q1 through Q4, with Q1 the lowest and Q4 the highest, pg/ml). Data were analyzed by PROC CORR, GLM or chi-squared using SAS. Mean serum AMH was $182 \pm 11 \mathrm{pg} / \mathrm{ml}$ and ranged from 0 to $1112 \mathrm{pg} / \mathrm{ml}$. There was no correlation between serum AMH and EBVs for NLB, NLW, MWWT, WWT and the maternal index. Serum AMH concentration was similar in ewes in different age categories $(P=0.157)$. There was a correlation between EBV for NLB $(0.29 ; P=0.0002)$ and NLW $(0.19 ; P=0.013)$ with average number of lambs born. Ewes in the lowest AMH quartile (Q1) had a lower mean number of offspring born from spring breeding compared with ewes in other AMH quartiles (Q2, Q3, and Q4; $P<$ 0.05). Further study is needed to determine the effectiveness of using serum AMH for selecting ewes for out-of-season (spring) breeding.
\end{abstract}

\section{Keywords}

Anti-Mullerian Hormone, Estimated Breeding Values, Out-of-Season Breeding, 
Reproductive Performance, Sheep

\section{Introduction}

Anti-Mullerian hormone $(\mathrm{AMH})$ is a dimeric glycoprotein that belongs to a member of the transforming growth factor- $\beta$ (TGF- $\beta$ ) family [1]. This hormone is produced by granulosa cells of pre-antral and small antral follicles of $1-3 \mathrm{~mm}$ diameter [2] [3]. Anti-Mullerian hormone facilitates follicle recruitment and growth of young follicles [4]. However, when a follicle increases in size, AMH limits the number of follicles developing from the gonadotropin responsive to the gonadotropin dependent stage [5]. Although AMH limits the number of ovulatory follicles, studies have positively correlated plasma AMH with fertility in sheep [6] [7]. Studies with cattle have shown that AMH concentration remains constant in an individual throughout the estrous cycle and during active reproductive age [3] [8] [9] [10].

It is well understood that individual ewes vary in reproductive performance, which is the basis for estimated breeding values (EBVs). Estimated breeding values (EBVs) are the mathematical predictions of the genetic merit of an animal for specific traits including reproduction. These values are calculated based on an individual animal's performance for a trait compared with animals within a contemporary group, and animals in other genetically connected flocks. Estimated breeding values are useful to select for reproductive or maternal traits used in breeding or commercial Katahdins, including prolificacy or number of lambs born (NLB) or weaned (NLW), or maternal weaning weight (MWWT), weaning weight (WWT), and maternal index

(http://www.nsip.org/). As lambs, EBVs are an estimate of the parent's genetic potential until sufficient data is collected on an individual and siblings. Similarly, the ability to conceive out-of-season also varies among ewes [11], but to date there is no way to predict whether an animal is likely to breed out-of-season. It is useful to predict reproductive performance of ewes early in life to minimize costs to rear the most efficient ewes.

Studies are lacking on relationship between serum concentrations of AMH and maternal EBVs in ewes, or out-of-season breeding success. Therefore, the objective of this study was to examine the relationship between serum AMH, mean number of lambs born (in spring, out-of-season or fall), and EBV for NLB, NLW, MWWT, WWT, and the maternal index.

\section{Materials and Methods}

The experiment was conducted at USDA, Agriculture Research Service (ARS), Dale Bumpers Small Farms Research Center (DBSFRC) in Booneville, AR, USA $\left(35.08^{\circ} \mathrm{N}, 93.98^{\circ} \mathrm{W}\right)$. All animal procedures were approved by ARS Institutional Animal Care and Use Committee (protocol \# 170103). 


\subsection{Animal Management}

Katahdin ewes were raised at USDA, ARS, DBSFRC in Booneville, AR. A total of 163 ewes ranging from 0.7 to 7 years of age were categorized into 5 age groups: less than $1(\mathrm{n}=17), 1$ to $2(\mathrm{n}=57), 2$ to $3(\mathrm{n}=23), 3$ to $4(\mathrm{n}=34)$, and more than 4 years of age $(\mathrm{n}=32)$. Ewes were maintained on predominantly tall fescue (Schedonorus arundinacea) and/or bermudagrass (Cynodon dactylon) overseeded with winter annuals [Wheat (Triticum aestivum L.) and rye (Lolium multiforum L.)] and were supplemented with corn/soybean meal (17\% CP, 82\% TDN on DM basis). Rams passed breeding soundness evaluation before breeding, and ewes were over 6 months of age and weighed at least $35 \mathrm{~kg}$. Ewes were exposed to rams for approximately 30 days either in fall (August/September) or spring (April/May) at a ram to ewe ratio of 1:20 to 1:30. Body weight of ewes was recorded on first day of ram exposure, and offspring were weighed at birth and approximately 60 days of age.

In some years ewes that would have been eligible to breed in fall were held over for spring to increase number of ewes available at that time. Pregnancy rate was determined (approximately 28 days after ram removal) by ultrasound examination (Aloka SSD $500 \mathrm{~V}$ ultrasound scanner equipped with a $7.5 \mathrm{MHz}$ linear array prostrate transducer; Hitachi Aloka Medical Ltd., Japan). Ewes that did not conceive to two consecutive breedings were removed from the flock. Other management criteria for culling ewes included problems of foot scald and internal parasites. Data on lambs, including pedigrees, body weight at birth, 60 and 90 - 120 days of age were entered in the US National Sheep Improvement Program (NSIP; http://www.nsip.org/) between 2008 and 2017 to generate EBVs in the flock. The EBVs included MWWT, WWT, NLB, NLW, and a Katahdin maternal index $(0.246 \times \mathrm{WWT}$ EBV $+2.226 \times \mathrm{MWWT} \mathrm{EBV}+0.406 \times \mathrm{NLW}$ EBV $-0.035 \times$ NLB EBV; Notter, 2011). Accuracies of EBVs for NLB for ewes used in the current study ranged from $35 \%$ to $72 \%, 31 \%$ to $67 \%$ for NLW, $57 \%$ to $79 \%$ for MWWT, and $55 \%$ to $81 \%$ for WWT. A definition of all EBVs is at http://nsip.org/wp-content/uploads/2015/03/NSIP-EBV-Descriptions-FINAL-1. 16.15.pdf (accessed February 19, 2019).

Blood was collected in July 2015 by jugular venipuncture into $10 \mathrm{ml} \mathrm{BD} \mathrm{Va-}$ cutainer SS Plus Blood Collection Tubes (Becton, Dickson, Franklin Lakes, NJ). Blood tubes were inverted to mix several times and allowed to clot for $30 \mathrm{~min}$ at room temperature. After clotting, the tubes were held on ice until centrifuged (Beckman Coulter T J6 refrigerated centrifuge, Fullerton, CA) at $2500 \times \mathrm{g}$ for 25 min. Serum was collected and stored in $5 \mathrm{ml}$ polypropylene tubes at $-20^{\circ} \mathrm{C}$ until analysis.

\subsection{Ovine AMH ELISA Immunoassay}

The equine and ovine AMH ELISA kit used was a quantitative three-step sandwich type immunoassay (AL-115, AnshLabs, Webster, TX). Analysis was performed as described by the manufacturer (http://www.anshlabs.com/). Before 
analysis, all the kit reagents were warmed to room temperature and serum samples were thawed overnight at $4^{\circ} \mathrm{C}$. Solutions were mixed as recommended. Calibrators were serially diluted from $50 \mathrm{pg} / \mathrm{ml}$ to $13,600 \mathrm{pg} / \mathrm{ml}$ of AMH. Fifty microliters of duplicate calibrators, control or serum samples were added to appropriate wells of the 96-well assay plate. Fifty microliters of AMH assay buffer was added to each well using a repeater pipette. Plate was shaken at $700 \mathrm{rpm}$ on an orbital microplate shaker (Lab-Line Instrument Inc. Melrose Park, IL) for $2 \mathrm{~h}$ at room temperature. The plate was removed and washed 5 times with wash solution in microplate strip washer (ELP40 Bio-Tek Instruments, New York, NY). Antibody-Biotin Conjugate RTU $(100 \mu \mathrm{l})$ was added using a repeater pipette, incubated at $700 \mathrm{rpm}$ on orbital microplate shaker (Lab-Line Instrument Inc. Melrose Park, IL) for $1 \mathrm{~h}$ and washed 5 times with wash solution using the microplate strip washer. Streptavidin-enzyme conjugate-RTU (100 $\mu \mathrm{l})$ was added after washing, incubated in the orbital microplate shaker at $700 \mathrm{rpm}$ for $30 \mathrm{~min}$, and washed 5 times using microplate washer. TBM chromogen $(100 \mu \mathrm{l})$ was added to each well using a repeated pipette and incubated in orbital microplate shaker at $700 \mathrm{rpm}$ for $20 \mathrm{~min}$. Finally, $100 \mu \mathrm{l}$ of stopping solution was added to each well and absorbance was read using a model 1420-040 Victor3 Multilabel Counter (Perkin Elmer, USA) at $450 \mathrm{~nm}$.

\subsection{Statistical Analysis}

For analysis, pregnancy rate is defined as the proportion of ewes that were pregnant approximately 28 days after ram was removed from breeding groups. One ewe did not lamb after being diagnosed as pregnant, but all other ewes determined pregnant post-breeding lambed. Mean number of lambs born was the number of live lambs born per ewe exposed to ram. Parity was the number of times individual ewes were used for breeding. Anti-Mullerian hormone concentrations were expressed either quantitatively or categorically into quartiles (Q1 through Q4, with Q1 lowest and Q4 highest; pg/ml). Quartiles were assigned using Excel Quartile function on raw data.

Pearson correlation coefficients between AMH, EBVs, and number of lambs born were analyzed using the PROC CORR procedure of SAS (version 9.4; SAS Inst. Inc., Cary, NC, USA). For remaining data, continuous variables were analyzed by PROC GLM, and categorical variables were analyzed by chi-squared using SAS. For categorical data $\mathrm{AMH}$ concentrations were divided into four quartiles: Q1 = $0-80$ pg/ml, Q2 = $81-104$ pg/ml, Q3 = $105-248$ pg/ml, and Q $=249-1112 \mathrm{pg} / \mathrm{ml}$. Data were expressed as least squares means and standard error. Means were compared using Tukey's test.

\section{Results}

Intra-assay variability of $\mathrm{AMH}$ assays ranged from $6.6 \%$ to $8.3 \%$. Inter-assay variability between standards was $4.3 \%$. Least square mean serum concentration of $\mathrm{AMH}$ was $182 \pm 11 \mathrm{pg} / \mathrm{ml}$ and ranged from 0 to $1112 \mathrm{pg} / \mathrm{ml}$. 


\subsection{Correlation of EBVs with AMH Concentrations and Average Number of Lambs Born}

Serum AMH concentrations were not correlated with EBVs for NLB $(-0.02 ; P=$ 0.793), NLW $(-0.09 ; P=0.252)$, MWWT $(-0.02 ; P=0.712)$, WWT $(-0.02 ; P=$ $0.757)$, and the maternal index $(0.072 ; P=0.355)$. Average number of lambs born was significantly correlated with EBV for NLB $(0.29 ; P=0.0002)$ and NLW $(0.19 ; P=0.013)$. However, EBV for WWT $(-0.09 ; P=0.242)$, MWWT $(-0.11 ; P$ $=0.138)$, and maternal index $(0.04 ; P=0.547)$ were not correlated with average number of lambs born.

\subsection{Relationship between AMH Quartiles and Mean Number of Lambs Born from Spring (Out-of-Season) or Fall Breeding}

There was no correlation between AMH quartiles with mean number of lambs born from fall breeding $(P>0.05$; Table 1$)$. However, there was a significant correlation between mean number of lambs born from spring breeding with AMH quartiles $(P<0.05)$. Ewes in lowest quartile (Q1) had lower number of lambs born from spring breeding than ewes in other quartiles (Q2, Q3, Q4; $P<0.05)$.

\subsection{Influence of Ewe Age on Serum AMH Concentration}

Mean AMH concentration in age groups of less than 1,1 to 2, 2 to 3, 3 to 4 , and more than 4 -years was $129 \pm 20,148 \pm 10,159 \pm 20,195 \pm 10,166 \pm 10 \mathrm{pg} / \mathrm{ml}$, respectively. There was no difference in serum AMH concentration among age categories $(P=0.157)$.

\subsection{Pregnancy and Lambing Rate of Exposed Ewes between Breeding Seasons}

Overall pregnancy rate was higher $(P<0.01)$ in fall bred ewes $(79.0 \%)$ compared with spring bred $(48.0 \%)$. Mean number of lambs born from fall breeding (1.44 $\pm 0.05)$ was higher $(P<0.01)$ compared with mean number of lambs born from spring breeding $(0.78 \pm 0.05)$ per ewes used for breeding.

\subsection{Lambing Rate per Parity}

Lambing rate was highest in third parity ewes and lowest in first parity ewes $(P<$ 0.05). Mean numbers of lambs born at first, second, third, fourth, fifth, and sixth

Table 1. Relationship between AMH quartiles and mean number of lambs born from different spring or fall breeding. Data expressed in mean \pm standard error (SE).

\begin{tabular}{cccccc}
\hline AMH Quartiles & AMH Range $(\mathrm{pg} / \mathrm{ml})$ & $\mathbf{n}$ & Fall & Spring & Overall \\
\hline AMHQ1 & $0-80$ & 37 & $1.48 \pm 0.11$ & $0.41 \pm 0.12^{\mathrm{b}}$ & $0.65 \pm 0.10$ \\
AMHQ2 & $81-104$ & 34 & $1.54 \pm 0.11$ & $0.92 \pm 0.11^{\mathrm{a}}$ & $0.81 \pm 0.11$ \\
AMHQ3 & $105-248$ & 39 & $1.38 \pm 0.11$ & $0.89 \pm 0.10^{\mathrm{a}}$ & $0.87 \pm 0.10$ \\
AMHQ4 & $249-1112$ & 36 & $1.43 \pm 0.10$ & $0.90 \pm 0.10^{\mathrm{a}}$ & $0.71 \pm 0.11$
\end{tabular}

Means with different superscripts in the same column differ $(P<0.05) . \mathrm{n}=$ number of ewes in each AMH Quartiles category. 
parity are $0.81 \pm 0.07,1.06 \pm 0.08,1.52 \pm 0.09,1.34 \pm 0.10,1.09 \pm 0.14$, and 1.33 \pm 0.21 , respectively.

\section{Discussion}

The mathematical calculations of EBVs are complex, taking into account of phenotypic (body weights, type of birth) and genetic (using data from relatives entered into NSIP) parameters. The EBV is the best estimate of the true genetic merit of any individual for a specific genetic trait measured (http://www.nsip.org/). The more data or genetic connections within the breed, the greater the accuracy of the EBV [12]. In the current study, there was no correlation between serum $\mathrm{AMH}$ concentrations and any of the EBVs. The priority selection criteria of the flock was parasite resistance followed by maternal traits (maternal milk and number of lambs weaned). Among the ewes in the flock, there was a wide range of EBV for maternal traits. Accuracy of some of these traits, especially in younger ewes may be low enough to impact correlations. Estimated breeding values for NLB as well as NLW in the current study were correlated with mean number of lambs born. The flock also had a higher value correlation between NLB and $\mathrm{NLW}$, implying that there is low voluntary lamb removal (i.e., artificial rearing of lamb or fostering of lambs to other ewes) [13]. However, other EBVs, WWT, MWWT, and maternal index were not correlated. The EBVs, NLW and MWWT are related to mothering ability, which physiologically is related to functional hormones post-lambing such as prolactin. Thus, EBVs for NLB and NLW can be further explored to select highly prolific ewes in the flock with good mothering ability.

Ovarian follicular population, an indicator for fertility, was positively correlated with plasma AMH concentration in young lambs [6] [7]. A positive correlation between plasma $\mathrm{AMH}$ concentrations during the prepubertal period and occurrence of ovulation in response to eCG was also reported [6]. A higher number of embryos were found in synchronized ewes with higher plasma AMH concentrations [14]. Ewes with a high plasma AMH ( $>97 \mathrm{pg} / \mathrm{ml})$ had a higher number of lambs born per ewe per year until 3.5 years of age compared with low (<97 pg/ml) plasma AMH concentrations measured at 3.5 months of age [7]. Because, AMH concentration remains constant throughout the estrous cycle and during active reproductive age [3] [8] [9] [10], we chose to examine this hormone in a range of age groups of sexually mature ewes. In the current study, when ewes were compared, based on serum AMH measurement after puberty, $\mathrm{AMH}$ hormone concentration was not correlated with mean number of lambs born. Similar results were obtained when ewes were compared by quartiles, based on serum AMH measurement after puberty with mean number of lambs born (not shown in the result). However, when number of lambs born from spring and fall breeding were separately correlated with AMH quartiles, ewes in lowest quartiles (Q1) had lower number of lambs born from spring breeding than ewes in other quartiles. Low reproductive performance of ewes in lowest 
quartiles (Q1) during spring in the current study is similar to the result we recently reported in cattle [15]. In our previous study, we reported AMH concentration of heifers at breeding, with the lowest quartiles (Q1) had lower AI pregnancy rate and conceived at a later estrus cycle in breeding compared with heifers in higher quartiles [15].

Out-of-season breeding during long days is beneficial to the sheep industry for several reasons. First, breeding in the spring results in late-gestation and lactation coinciding with rise in high quality cool-season forage in the southeastern US [16]. Second, weather in early fall is ideal for pasture lambing, reducing chances of weather related deaths in young [17]. Third, lambs can be marketed in spring when demand is high and the lamb supply is low [18]. In much of the US, pregnancy and lambing rates are higher during fall breeding compared with spring, and Katahdins in the Southeastern US are no exception [11]. Katahdin ewe lambs or yearlings have more pregnancy losses, and lower lamb birth weights when bred during spring compared with fall [11]. In order to increase spring breeding success, it will be useful to identify ewes that are capable of out-of-season breeding. In the current study, ewes in lowest AMH hormone quartiles had lower number of lambs born from spring (out-of-season) breeding, thus further study can be done to select ewes that can breed out-of-season by using AMH endocrine marker.

Anti-Mullerian hormone is high during the fetal stage compared with postnatal concentrations [2]. Similarly, plasma AMH concentrations in $40 \mathrm{~d}$ old ewes are higher than 3.6-month old ewes [6] [19]. Lahoz found a vast difference between 1 and 5-month-old ewes, decreasing with age [20]. Serum AMH concentrations of ewes after puberty, at different reproductive ages has not been reported. In the current study, serum AMH concentrations was similar in different age groups (less than one, $1-2,2-3,3-4$, and more than 4 year old) ewes. Age did not influence serum AMH concentrations as previously reported in cattle [8] [9].

\section{Conclusion}

In conclusion, serum AMH concentration was similar among age groups. Ewes in the lowest quartile (Q1) had lower number of offspring born from spring breeding compared with ewes in other AMH quartiles (Q2, Q3, and Q4). However, AMH was not useful in predicting fertility or maternal traits based on EBV of the ewes. Further research can be done to select ewes that are capable of out-of-season breeding using endocrine markers.

\section{Acknowledgements}

This research was supported by the University of Arkansas Division of Agriculture, and the USDA Agriculture Research Service. The authors acknowledge Lauretta Ngere, Chad Lee, Erin Wood, Toby Lester, and Samuel Tabler for their technical help. Mention of trade names or commercial products in this manu- 
script is solely for providing specific information and does not imply recommendations or endorsement by the authors or sponsoring organizations.

\section{Conflicts of Interest}

The authors declare no conflict of interest regarding this publication.

\section{References}

[1] Cate, R.L., Mattaliano, R.J., Hession, C., Tizard, R., Farber, N.M., Cheung, A., et al. (1986) Isolation of the Bovine and Human Genes for Müllerian Inhibiting Substance and Expression of the Human Gene in Animal Cells. Cell, 45, 685-698.

https://doi.org/10.1016/0092-8674(86)90783-X

[2] Bézard, J., Vigier, B., Tran, D., Mauléon, P. and Josso, N. (1988) Anti-Müllerian Hormone in Sheep Follicles. Reproduction Nutrition Development, 28, 1105-1112. https://doi.org/10.1186/1746-6148-8-118

[3] Monniaux, D., Drouilhet, L., Rico, C., Estienne, A., Jarrier, P., Touzé, J.L., et al. (2012) Regulation of Anti-Müllerian Hormone Production in Domestic Animals. Reproduction Fertility and Development, 25, 1-16. https://doi.org/10.1071/RD12270

[4] Scaramuzzi, R.J., Baird, D.T., Campbell, B.K., Driancourt, M.A., Dupont, J., Fortune, J.E., et al. (2011) Regulation of Folliculogenesis and the Determination of Ovulation Rate in Ruminatns. Reproduction Fertility Development, 23, 444-467. https://doi.org/10.1071/RD09161

[5] Campbell, B.K., Clinton, M. and Webb, R. (2012) The Role of Anti-Müllerian Hormone (AMH) during Follicle Development in a Monovulatory Species (Sheep). Endocrinology, 153, 4533-4543. https://doi.org/10.1210/en.2012-1158

[6] Lahoz, B., Alabart, J.L., Monniaux, D., Mermillod, P. and Folch, J. (2012) Anti-Mullerian Hormone Plasma Concentration in Prepubertal Ewe Lambs as a Predictor of Their Fertility at a Young Age. BMC Veterinary Research, 8, 2-9. https://doi.org/10.1186/1746-6148-8-118

[7] Lahoz, B., Alabart, J.L. and Folch, J. (2016) Relationship between Anti-Müllerian Hormone (AMH) and the Ovulatory Response Measured in Three-Month Old Ewe Lambs with Their Reproductive Efficiency in Adulthood. Associatión Interprofesional para el Desarrollo Agrario, 112, 392-404. https://doi.org/10.12706/itea.2016.024

[8] Rico, C., Fabre, S., Médigue, C., Clemente, N., Clément, F., Bontoux, M., et al. (2009) Anti-Müllerian Hormone Is an Endocrine Marker of Ovarian Gonadotropin-Responsive Follicles and Can Help to Predict Superovulatory Responses in the Cow. Biology of Reproduction, 80, 50-59.

https://doi.org/10.1095/biolreprod.108.072157

[9] Ireland, J.J., Smith, G.W., Scheetz, D., Jimenez-Krassel, F., Folger, J.K., Ireland, J.L.H., et al. (2010) Does Size Matter in Females? An Overview of the Impact of the High Variation in the Ovarian Reserve on Ovarian Function and Fertility, Utility of Anti-Mullerian Hormone as a Diagnostic Marker for Fertility and Causes of Variation in the Ovarian Reserve in Cattle. Reproduction Fertility and Development, 23, 1-14. https://doi.org/10.1071/RD10226

[10] Mossa, F., Jimenez-Krassel, F., Scheetz, D., Weber-Nielsen, M., Evans, A.C.O. and Ireland, J.J. (2017) Anti-Mullerian Hormone (AMH) and Fertility Management in Agricultural Species. Reproduction, 154, R1-R11. 
https://doi.org/10.1530/REP-17-0104

[11] Burke, J.M. (2005) Lamb Production of Dorper, Katahdin, and St. Croix Bred in Summer, Winter, or Spring in the Southeastern US. Sheep and Goat Research Journal, 20, 51-59.

[12] Kuehn, L.A., Lewis, R.M. and Notter, D.R. (2007) Managing the Risk of Comparing Estimated Breeding Values across Flocks or Herds through Connectedness: A Review and Application. Genetics Selection Evolution, 39, 225-247. https://doi.org/10.1051/gse:2007001

[13] Notter, D.R., Lauretta, L., Burke, J.M., Miller, J.E. and Morgan, J.L. (2018) Genetics Parameters for Ewe Reproductive Performance and Peri-Parturient Fecal Egg Counts and Their Genetic Relationships with Lamb Body Weights and Fecal Egg Count in Katahdin Sheep. Journal of Animal Science, 96, 1579-1589.

https://doi.org/10.1093/jas/sky100

[14] Pinto, P.H.N., Balaro, M.F.A., Souza-Fabjan, J.M.G., Ribeiro, L.S., Braganca, G.M., Leite, et al. (2018) Anti-Mullerian Hormone and Antral Follicle Count Are More Effective for Selecting Ewes with Good Potential for in Vivo Embryo Production than the Presence of FecGE Mutation or eCG Pre-Selection Tests. Theriogenology, 113, 146-152. https://doi.org/10.1016/j.theriogenology.2018.02.018

[15] Rorie, R., Newberry, H., Lester, T.D., Acharya, M. and Hansen, C. (2016) Anti-Müllerian Hormone at Weaning and Breeding as a Predictor of Beef Heifer Fertility. Reproduction Fertility and Development, 29, 111-112. https://doi.org/10.1071/RDv29n1Ab8

[16] Volesky, J.D., Anderson, B.E. and Nichols, J.T. (2010) Perennial Forages for Irrigated Pasture. Nebraska Extension. http://extensionpublications.unl.edu/assets/html/g1502/build/g1502.htm

[17] USDA-APHIS-VS-CEAH-NAHMS (2014) Sheep and Lamb Death Loss in the United States, 2011. National Animal Health Monitoring System. Animal and Plant Health Inspection Service, Fort Collins. https://www.aphis.usda.gov/animal_health/nahms/sheep/downloads/sheep11/Sheep 11_is_DeathLoss.pdf

[18] American Lamb Board (2018) National Lamb Check-Off Program. https://www.americanlamb.com

[19] Torres-Rovira, L., Gonzalez-Bulnes, A., Succu, S., Spezzigu, A., Manca, M.E., Leoni, G.G., et al. (2014) Predictive Value of Antral Follicle Count and Anti-Müllerian Hormone for Follicle and Oocyte Developmental Competence during the Early Prepubertal Period in a Sheep Model. Reproduction Fertility and Development, 26, 1094-1106. https://doi.org/10.1071/RD13190

[20] Lahoz, B., Fabre S., Calvo, J.H., Drouilhet, L., Sanchez, P., Sarto, P., et al. (2016) Assessing the Age-Related Relationship between Plasma Anti-Mullerian Hormone $(\mathrm{AMH})$ and Ovarian Follicle Population in Prepubertal Ewes. 18th International Congress on Animal Reproduction (ICAR), Tours, 26-30 June 2016, 41.

https://araid.es/en/content/assessing-age-related-relationship-between-plasma-antim\%C3\%BCllerian-hormone-amh-and-ovarian 